\title{
ISLAM POSMODERNISME
}

\author{
Muslim Abdurrahman
}

Al Maun Institut Jakarta

\section{Abstract}

In this modern era, Islam, in fact, has a significant influence in politics and culture. Western people regard this as a symptom of the emergence of Islamic fundamentalism. It is a reaction of Islam to modernism and capitalism. Even though the term is not purely from Islamic terminology, for Western academicians it virtually represents Islam. Even, they relate it to terrorist movements. It takes us back to remarkable phenomena of secularism embedding that happened in Europe two decades ago. Modernism and capitalism have effects not only on Islam but also on other non-Islamic countries. Therefore, it is not surprising if then in this era of global capitalism Western academicians try to eliminate the thesis of secularism in their fundamentalism project. In the third millennium, after the fall of communism in Russia and Western Europe, Western is interested in studying Islam, if truth to be told, it is more intense. They are afraid of the influence of Islam for which the fundamentalists struggle to realize Islam as the grand narrative, a blue print of universal ideology that often impedes Western hegemony with its liberal democracy.

Key words: post-modernism, fundamentalism

\section{Pendahuluan}

Selama ini, dalam bacaan sosiologi agama, pernah dibayangkan bahwa perkembangan kapitalisme dan modernisasi akan mengakibatkan merosotnya pengaruh agama dalam masyarakat. Hal ini terutama akan menimpa negara-negara dunia ketiga, setelah mereka mengalami proses industrialisasi. Sejarah kristenisasi dalam dua dasawarsa lalu di Eropa memang membuktikan terjadinya sekularisasi, tapi dalamabadkedua puluh ini perkembangan islam menunjukkan gejala sebaliknya. Ternyata,' Islam malah mempunyai pengaruh yang kuat dalam politik maupun lapangan kebudayaan, bahkan itu tidak hanya terjadi di timur namun Islam juga 
mengokohkan pengaruhnya di Barat. Kuatnya Islam dalam proses industrialisasi ini menimbulkan pertanyaan yang mendasar, yakni apa sesungguhnya watak dari budaya modern itu sendiri?

Apa yang lebih menarik, gejala tentang reaksi Islam terhadap modernisasi ini kemudian didokumentasikan oleh Barat sebagai munculnya "Fundamentalisme Islam," suatu penamaan yang sesungguhnya tidak murni berasal dari kaum muslimin sendiri. Di dunia akademik Barat, terutama setelah revolusi Iran, hampir-hampir istilah ini menjadi representasi Islam, yang dalam media massa Barat sering diidentikkan sebagai gerakan terorisme sesungguhnya, gejala fundamentalis agama sebagai reaksi terhadap kapitalisme dan terorisme bukanlah monopoli Islam, karena dikalangan umat lain di negeri-negeri non islam juga terjadi hal yang sama. Oleh karena itu, tidak heran dalam era kapitalisme global, kajian-kajian sosiologis agama yang dilakukan oleh akademik Barat sekarang ini telah menghapus tesis sekularisasi itu dengan proyek-proyek "Fundamentalis" yang dibiayai secara besar-besaran.

Pada waktu belakangan ini, terutama setelah jatuhnya komunis di Rusia dan Eropa Barat, minat Barat untuk melakukan kajian Islam jelas lebih serius lagi. Hal ini karena mereka khawatir tentang pengaruh Islam yang disuarakan oleh kalangan fundamentalis yang bertujuan untuk menjadikan Islam sebagai "grand narrative", suatu cetak biru ideologi dunia yang selalu menghadang hegemoni barat yang selama ini menjagokan demokrasi liberal.

Itulah sekilas tentang posisi Islam dalam percaturan politik dan akademik Barat dewasa ini, sebagai rekonstruksi sebelum hal ini dikaitkan dengan diskusi yang menggejala akhir-akhir ini tentang posmodernisme dan pos-modernisasi. Sudah tentu, kedua istilah ini yakni: "posmodernisme" dan "pos-modernisasi" lebih dulu dijernihkan, karena yang pertama lebih menggambarkan paham, format atau aliran berfikir, sementara yang kedua menunjukkan sebuah keadaan.

\section{Posmodernisme dan Posmodernisasi}

Seperti kita ketahui, awalnya isu tentang "posmo" berasal dari aliran di dalam seni sebagai kritik terhadap modernisme yang menghasilkan seni- 
seni tinggi, milik kaum borjuasi. Posmo ini, sebagai kritik teori, kemudian merembet ke bidang literatur atau sastra, terutama berkaitan dengan persoalan hermeneutic. Sekarang ini posmo telah menjadi kecenderungan aliran baru yang memasuki semua disiplin humanities ilmu-ilmu sosial.

Bagi kebanyakan intelektual barat, mereka antusias terhadap filsafat posmodernisme, tidak lain untuk memenuhi kebutuhan terhadap memudarnya ideologi sosialisme yang selama ini diharapkan mampu menghadapi sistem kapitalisme. Dalam hal ini, mengikuti apa yang dikatakan oleh J. F. Lyotard dalam tulisannya yang hampir klasik berjudul: "The Postmoderism Condition"(1984), secara gampangnya kita bisa mendefinisikan "posmodernisme" sebagai ketidak percayaan terhadap kemampuan pemikiran besar dari gagasan-gagasan positivisme selama ini (metanarratives). Pemikiran posmodernisme, oleh karena itu, merupakan reaksi yang mengecam terhadap bentuk penindasan kapitalisme dan sekaligus juga menolak kekuasaan birokrasi sosialisme otoriter.

Sebagai reaksi terhadap kapitalisme mutakhir, maka dari sudut pandangan sosiologis, sudah jelas bahwa posmodernisme sangat peduli terhadap resiko-resiko sosial, budaya dan ekonomi yang dihadirkan oleh posmoderniti. Yakni suatu keadaan pos modern yang dilukiskan sebagai perkembangan mutakhir dari konsumerisme, pengorganisasian kembali kota-kota pada akhir abad kedua puluh, pengaruh-pengaruh yang diakibatkan oleh bentuk tegnologi baru terhadap kehidupan sosial, konsekuensi dari turisme global dan meningkatkan resiko kerusakan alam dan lingkungan akibat kapitalisme dunia yang tak terkendali.

Ada juga kritik, memang, yang dialamatkan kepada para penganjur posmodernisme sebagai gagasan alternatif yang dianggap tak jelas apa pesan politiknya. Sebab, sering kali terkesan bahwa posmodernisme hanyalah peduli pada prinsip hak-hak untuk berbeda saja (difference). Tapi, saya kira, sulit dibantah bahwa posmodernisme sekarang ini tidak hanya hidup dalam tingkat perdebatan politik, tapi paham itu telah menjadi semangat baru bagi mereka yang aktif dalam gerakan-gerakan. Di dunia feminisme, misalnya, posmodernisme telah menjadi landasan berfikir dan acuan untuk melakukan pembebasan dari ide uniformitas, patriarkal, rasionalis dan kekuatan struktur-struktur hirarkis yang selama ini dibentuk oleh 
modernisme barat. Oleh karena itu, posmodernisme mengajukan perlunya sebuah visi baru yang adil yang memberi ruang terhadap perbedaan, kemajemukan, paradoks dan kontradiksi, bahkan perlunya menghormati sistem nilai dan pengetahuan lokal yang dimiliki oleh masyarakat (Turner 1990).

Di dunia antropologi, lahirnya posmodernisme telah memperkuat keinginan tentang menghormati sistem kepercayaan dan pengetahuan lokal itu, dengan mempersoalkan kembali dasar-dasar ethnografi sebagai salah satu bentuk reprentasi budaya masyarakat yang ditelitinya (Clifford 1988, Appardurai 1990). Pertanyaan-pertanyaan itu menyangkut apa otoritas yang bisa dijadikan dasar otentisitas menulis ethnografi dan ilmu-ilmu sosial yang benar-benar berangkat dari empiri masyarakat dunia ketiga (third-world society) yang juga benar-benar bebas dari tradisi orientalisme.

Sebagai ilmu-ilmu sosial klasik, antropologi memang sangat peduli dengan persoalan makna, tafsiran terhadap simbol-simbol, dan pencarian ungkapan-ungkapan kehidupan manusia, melalui analisa budaya. Oleh klarena itu, dalam batas-batas tertentu, anthropologi sebenarnya merupakan sebuah penyelidikan hermeunetik terhadap system keyakinan yang dianut masyarakat, upacara-upacara keagamaan, dan praktek-praktek tradisi. Masuknya posmodernisme kedalam disiplin anthropologi telah memperkuat dimensi penyelidikan sosio-kultural itu, yang menekankan selalu membaca teks-teks budaya yang telah berubah dengan cepat, melalui kamampuan analisis detail terhadap keadaan yang penuh ironi, parody, dalam satire dan ungkapan-ungkapan budaya lainnya yang bersifat hermeneutic. Itu artinya bahwa pemahaman anthropologi harus mulai meninggalkan cara pandang dan pendekatan yang selama ini mengsumsikan tentang adanya kesamaan uneversalistik mengenai siknifikansi agama, ritual, dan sistemsistem kepercayaan (Turner, 1994). Sebab, simbol-simbol kebudayaan yang dihasilkan oleh kapitalisme mutakhir, memang tidak mungkin lagi bisa dibaca dalam kekuatan politik ekonominya yang material, atau dalam maknanya yang univocal. Dalam hal ini, berarti, teks-teks kebudayaan termasuk Islam sekarang telah menjadi daerah yang diperebutkan tafsirannya oleh para pengikutnya sendiri dimana-mana (Fiscer, M.J. dan Mehdi Abedi, 1990). 


\section{Islam dan Posmodernisme}

Sekarang, apa kaitan Islam dengan posmodernisme ini? Sebagai bahan untuk membahas ini, barang kali ada baiknya saya merujuk pada dua buku, yang akhir-akhir ini memperoleh perhatian besar berkenaan dengan tinjauan Islam dan posmodernism. Dua buku ini dianggap kembar, sebab semula dipersiapkan sebagai pasangan yang akan diterbitkan bersamasama oleh penerbitnya, yakni Routledg, di London. Kedua pengarangnya mempunyai disiplin yang sama, yaitu: anthropologi. Pertama, buku Ernest Gelner berjudul: Postmodernism, Reason and Relegion (1992). Dan kedua buku Akbar Ahmed yang berjudul: Postmodemism and Islam (1992).

Hampir bisa disimpulkan bahwa keseluruhan pembahasan Gellner tentang fundamentalisme dan posmodernisme diwarnai dengan argumentasi "rasioanalisme" yang ia banggakan. Bagi Gellner, fundamentalisme dan posmodernisme merupakan dua kutub ekstrim yang berlawanan. Fundamentalisme percaya akan sebuah kebenaran yang unik untuk pengikutnya saja. Sementara itu, katanya, posmodernisme berupaya menghentikan ide tentang kebenaran yang unik itu dan berusaha memperlakukan setiap visi kebenaran yang ada tidak kurang dari segi kebenarannya. Menurut Gellner "rasionalisme" adalah pemecahan yang baik diantara dua pandangan yang ekstrim itu, namun percaya bahwa tidak mungkin kita bisa mencapai dan memiliki kebenaran itu sepenuhnya secara definitive. Oleh karena itu "rasionalisme" tidak mungkin menyatakan subtansi kebenaran itu sendiri, sebab rasionalisme itu hanya loyal pada ketentuan-ketentuan prosedurnya.

Gellner tidak mengungkapkan perubahan sosial apa dibalik munculnya fundamentalisme Islam itu. Halnya itu mengatakan bahwa masyarakat kini bertambah ilmiah dan semakin dipengaruhi oleh proses industri, sehingga pengaruh dan wibawa agama semakin naik, tapi agama yang mereka praktekkan tidak lain adalah agama sekuler atau agama cult seperti yang sering muncul dikalangan masyarakat Amerika. Islam, dalam pandangan Gellner, menyalahi perkembangan semacam itu, bahkan Islam telah menafikan tesis sekularisasi selama ini. 
Gejala munculnya fundamentalisme sangat kuat dikalangan Islam, karena menurut Gallner, berkaitan dengan soal "budaya tinggi" (high culture) dan "budaya rendah" (low culture), dimana budaya tinggi itu kini telah merasuk kesebagian besar kaum muslimin. Budaya tinggi itu, di dalam kehidupan umat Islam, telah berfungsi seperti halnya nasionalisme yang mengajarkan loyalitas dalm bingkai yang luas, dalam kesadaran kolektifitas tanpa batas yang pasti, dimana seseorang dan lainnya tidak perlu mengenal secara-pribadi (Gellner.1985). Mereka hanya diikat oleh identitas budaya, gaya berfikir, perasaan yang sama, dan sering kali juga menggunakan kesamaan bahasa-bahasa tertentu. Dalam hal ini, menurutnya, ada situasi yang paralel yang sangat penting antara nasionalisme itu dengan kaum fundamentalisme, karena fundamentalisme menekankan lewat anjuran kembali ke skriptualisme agar para pengikutnya menguasai literatur agama. Dengan menekankan kembali ke Qur'an, kaum muslimin yang puritan telah mengikatkan batinnya kepada sabda, dan dengan sabda Tuhan itu kesadarannya ditransendensikan untuk mengatasi segala batas primordialisme yang sempit. Sebagai contoh, orang-orang Melayu atau orang Somali, mereka dalam kesadaran ethnisitinya tidak bisa dilepasakan dengan keyakinan imannya terhadap Islam.

Dalam tulisannya yang lain (1994), Gellner menjelasakan bahwa memudarnya "high Islam of the scholars" dan "low Islam of the people", antara lain disebabkan perkembangan teknologi dan juga urbanisasi. Sehingga, teologi Islam skolastik yang dulunya hanya melayani sebagian elite, kini telah memasuki pasar umat dengan bebas. Umat islam urban, kini mereka lebih dekat dengan kitab sucinya, daripada ikatannya terhadap orang-orang suci yang selama ini sebagai panutan batin dan ikatan sosiologisnya. Mengapa hal ini terjadi? Gellner menduga, disebabkan nilai-nilainya memang pas bagi kehidupan modern. High Islamic culture itu mempunyai orientasi: individualisme yang kuat; aturan-aturan ethnic yang kokoh; sangat rendah muatan magisnya; berkaitan erat dengan skriptual-yang bagi kaum muslimin-nilai-nilai itu mampu menyelamatkan dari dilema kehidupan di alam modern sekarang ini. Yakni kesulitan antara memilih menjadi "Barat" dengan sulitnya melakukan idealisasi tradisi lokal warisan nenek moyang. 
Adapun buku Ahmed tentang Islam dan posmodenersme, menurut saya, argumentasinya sangat elektik. Pada intinya dia mengajukan agar umat islam mampu melakukan rekonsiliasi terhadap tradisi-tradisinya berhadapan denagn perkembangan modernitas yang sekuler yang kini merasuki segenap kehidupan. Dalam kaitan itu, ia menganjurkan agar umat Islam mau menoleh kepos-modernisme sebagai pilihan. Evaluasi Ahmed tentang posmodernisme sendiri sangat positif, yang sangat berbeda dengan penilaiannya terhadap modernisme sebagai mana halnya yang selama ini diketengahkan oleh tokoh-tokoh Islam berpendidikan Barat. Pandangan ini sangat berbeda denagn Gillner lebih mengunggulkan rasionalisme modern. Dalam pandangan Ahmed, rasionalisme itu sekarang tidak memperoleh tempat yang baik dalam opini kaum muslimin sendiri.

Dalam keseluruhan penjelasan Ahmed, buku ini sangat tendensius karana menyimpulkan bahwa moral Barat telah bangkrut, mereka itu "bohong", munafik, dan korup. Pernyataan semacam ini jelas mencerninkan semangat kritik yang fulgar terhadap Barat, sambil dalam buku ini Ahmed memperingatkan para pemimpin Islam agar melihat perkembangan posmodernisme sebagai tantangan, posmodernisme yang berkibar pada tahun sembilan puluhan, kata Ahmed, telah menggedor pintu umat Islam dimanamana, tentang perlunya menghidupkan kembali semangat ijtihad. Ahmed, lewat bukunya itu, juga mengingatkan tentang pengaruh media Barat yang sangat kuat dewasa ini yang jelas menjadi ancaman potensial bagi kehidupan keislaman. Ia menunjuk Madonna adalah simpul (the sign) dari apa yang dikatakan sebagai era pos-modernisme yang mengancam otoritas kelakilakian (manhood) dan kebenaran.

Sebelum memperbincangkan secara lebih jauh tentang apa yang telah diungkapkan Gallner dan Ahmed mengenai Islam dan posmodernisme, barang kali ada beberapa hal yang harus dipertegas.

Dalam diskursus akademik sendiri sebenarnyabelum ada kesepakatan tentang apa itu yang disebut sebagai: posmodernisme dan posimoderniti. Misalnya saja, sampai saat ini mereka belum bisa menjawab: apakah keadaan posmoderniti itu kelanjutan dari era modernity, ataukah keadaan yang berlawanan dengan modernity? Jika merupakan kelanjutan, selanjutnya ataukah posmoderniti merupakan bentuk dari keadaan high modemity?. 
Lepas dari belum terjadinya kesepakatan mereka menjawab pertanyaanpertanyaan dasar seperti itu, ada hal yang sangat jelas bahwa posmodernisme adalah merupakan kritik filsafat terhadap keangkuhan grand narratives yang tidak memberikan hak hidup untuk berbeda. Sementara itu, posmoderniti sebagai keadaaan sosial dari the late capitalism, merupakan gejala globalisasi, fragmentasi gaya hidup, hyperkonsumerisme, deregulasi financial pasar dan peralatan politik, mengguritanya kekuasaan Negarabangsa, dan kuatnya pengaruh iklan melalui canggihnya perkambangan simulasi komputr dan elektronik.

Sejalan dengan itu, jika islam seperti dikehendaki oleh Ahmed yang harus berani menentang terhadap ancaman dari tokoh pengebirian seperti Madona, berarti islam tidak lain ingin muncul juga sebagai "grand narative". Itu artinya bahwa islam jiga membutuhkan perlindungan dari proses sosial tentang diversifikasi seksual dan budaya yang diwakili oleh idola seperti Madona dan Michael Jackson. Padahal sudah jelas bagaimana pun, baik pos-modernisme maupun posmoderniti, dua-duanya bisa menentang nilainilai dan kelembagaan agama yang ada selama ini. Islam sebagai narrative kebenaran ang diyakini oleh para pemeluknya, mau tidak mau harus menghadapi erosi makna yang dilansir oleh program komersial TV, MTV, Video, dan jaringan global iklan sekarang ini, mungkin benar apa yang dikatakan oleh Ahmed bahwa ancaman terbesar yang dihadapi islam saat ini, bukanlah apa yang diwariskan Jesus, tetapi apa yang telah ditampilkan oleh Madona idola dari zaman posmoderniti. Oleh Ahmed agar Islam mampu melakukan rekonsiliasi terhadap warisan tradisionalnya dengan perkembangan pos-modernism dan pos-moderniti, mencerminkan sikap embiguitinya, terutama dengan watak kerakusan yang dibawa olek konsumerisme pos-moderniti itu sendiri.

Ada pun Gellner, yang jelas-jelas awal karir antropologinya dikenal sebagai pejuang rasionalisme, dan dalam perdebatan ini sangat menyerang posmodernisme, bagi saya, ia sangat mengabaikan realitas-realitas sosial mutakhir yang seharusnya perlu dipertimbangkan. Yakni: diversifikasi budaya yang semakin meluas; disain utuh modernisasi yang ternyata menghasilkan fragmentasi budaya; yang semuanya itu memaksa semua orang dan kelompok masyarakat melakukan self-reflexive terhadap system keyakinan yang selama. 
ini telah mereka miliki. Sebab, kita semua ini hidup dalam masyarakat yang penuh resiko, baik karena tidak amannya lagi lingkungan alam maupun lingkungan sosial. Kondisi sosial semacam ini, tidak bisa lain kan menumbuhkan kesadaran diri secara global, bukan hanya pentingnya meralitifisir kepercayaan yang kikta miliki selama ini, namun diperllukan gerakan budaya yang mampu menjawab tantangan empiris yang dihasilkan oleh pos-modernity yakni; kehidupan sosial yang penuh resiko dan ketidak pastian normal.

Kelemahan yang paling mendasar dari Gillner dalam bukunya itu ialah bahwa semua pembahasannya dengan Islam kaitannya dengan posmodernisme, benar-benar hanya berangkat dari pendekatan ideal-type pada tingkat persoalan teologis. Kategori "fundamentalisme" yang ia angkat sebagai focus kaitannya dengan pos-moderniti, tampaknya lebih dekat pada perbincangan dalam diskursus intelektual atau perdebatan teologi yang muncul dikalangan ulama-ulama agama. Dan bukan dari keadaan sosial yang nyata sehari-hari. Sebab, kini yang terjadi setiap hari sebenarnya adalah proses relatifisme agama yang dipaksa melalui pertukaran komoditi secara global, travel dan masstourism, serta dampak jaringan TV dunia dan internet, yang setiap hari menyapa dasar-dasar keimanan dan moral penduduk bumi. Dalam bahasa Marxis, inilah proses sosial di mana kesadaran supra structur dikendalikan oleh kekuatan struktur, dan bukan sebaliknya. Oleh sebab itu, kehadiran konsumerisme Barat yang hedonis sebagai ancaman keimanan, barang kali akan lebih tepat untuk diamati pada akjian mikro dalam kehidupan sehari-hari pada sebuah masyarakat desa, ketimbang mengambil fokus pada tingkat elite keagamaan atau di kalangan intelektual.

\section{DAFTAR PUSTAKA}

Ahmed, Akbar S. 1992. Posmodernism and Islam. Predicament and Promise, London: Routledge.

Appadurai, Arjun. 1990. Disjunture and Difference in the Global cultural Economy, Theory, Culture and Society.

Asad, T. 1993. Geneologies of religion: Discipline and reasons of power in Christianity and Islam, Baltomore: Jhon Hopkins University Press. 
Fischer, M.J and Mehdi Abedi. 1990. Debating Muslim: Cultural Dialogues in Posmodemity and Tradition. Madison: Ubiversity of Wisconsin Press.

Gellner, Ernest ed. 1985. Islamic Dilemmas: Reformers, Nationalits and Industrialization. New York: Mouton

Routledge. 1992. Posmodernism, Reason and Relogion. London: 1994. Freword dalam Akbar S. Ahmed and Hasting Donnan (eds) Islam, Globalisation and Postmodernity. London: Routledge.

Giddens, A. 1991. Modernity and Self-Identity: Self and Society in the Late Modern Age. Cambridge: Polity press.

Harvey, D. 1989. The Condition of Postmodernity: An engquiry into the origins of cultural change. Oxford: Basil Blackwell.

Jameson, F. 1984. Posmodernism or the cultural logic of late capitalism, New Left Review.

Lyotard, J.F. 1984. The Posmodern condition, Minneapolis: University of Minnesota Press.

Turner. B.S (1990) Theories of Modernity and Postomodernity. London: Sage -1994. Orientalism, Posmodernism and Globalism, London:Routledge

Turner. G. 1990. Britis Cultural Studies, An introduction. London: Unwin Hyman. 